\title{
Nitroxide with diphenylphosphino moiety: synthesis, supramolecular structure, biology and catalysis
}

\author{
A. Bényei ${ }^{1}$, M. Isbera², B. Bognár ${ }^{2}$, F. Gallyas ${ }^{3,4,6}$, J. Jekö $^{5}$ and T. Kálai ${ }^{2}$
}

${ }^{1}$ Department of Pharmaceutical Chemistry, University of Debrecen, Egyetem tér 1, H-4032 Debrecen, Hungary, ${ }^{2}$ Institute of Organic and Medicinal Chemistry, Faculty of Pharmacy; University of Pécs, Szigeti st. 12, H-7624 Pécs, Hungary, ${ }^{3}$ Department of

Biochemistry and Medical Chemistry, University of Pécs Medical School, 7624 Pécs, Hungary, ${ }^{4}$ HAS-UP Nuclear-Mitochondrial

Interactions Research Group, 1245 Budapest, Hungary, ${ }^{5}$ Department of Chemistry, University of Nyirregyháza, Sóstói st. $31 / B, 4440$

Nyíregyháza, Hungary, 'János Szentágothai Research Center, University of Pécs, Ifjúság 20, H-7624 Pécs, Hungary

\author{
benyei.attilal@science.unideb.hu
}

The coupling of nitroxide and tertiary phosphane moieties offer unique opportunities in synthesis and catalysis as well as in biological effects. Surprisingly, no crystal structure report is found in CSD [1] for tertiary phosphane substituted pyrroline nitroxide. We first reported such structure [2] and synthesis of 3-(diphenylphosphino)-2,2,5,5-tetramethyl-2,5-dihydro-1H-pyrrol-1-yloxyl radical, 1, Fig.1., left. Structural data clearly indicate the expected nitroxide radical. Analysis of supramolecular structure gave interesting results (Fig. 1., right). A simple derivative had shown better antiproliferative effect on MDA-MB-231 and MCF-7 human breast cancer lines than MITO-CP indicating the potential of the compound for use in cancer therapy [3]. Moreover, inclusion of phosphane and nitroxide moiety into the same ligand suggest versatile homogeneous catalytic activity by both metal center and ligand assisted mechanisms and they may serve as organocatalysts, too. Further studies to explore these potentials are under way in our laboratories.
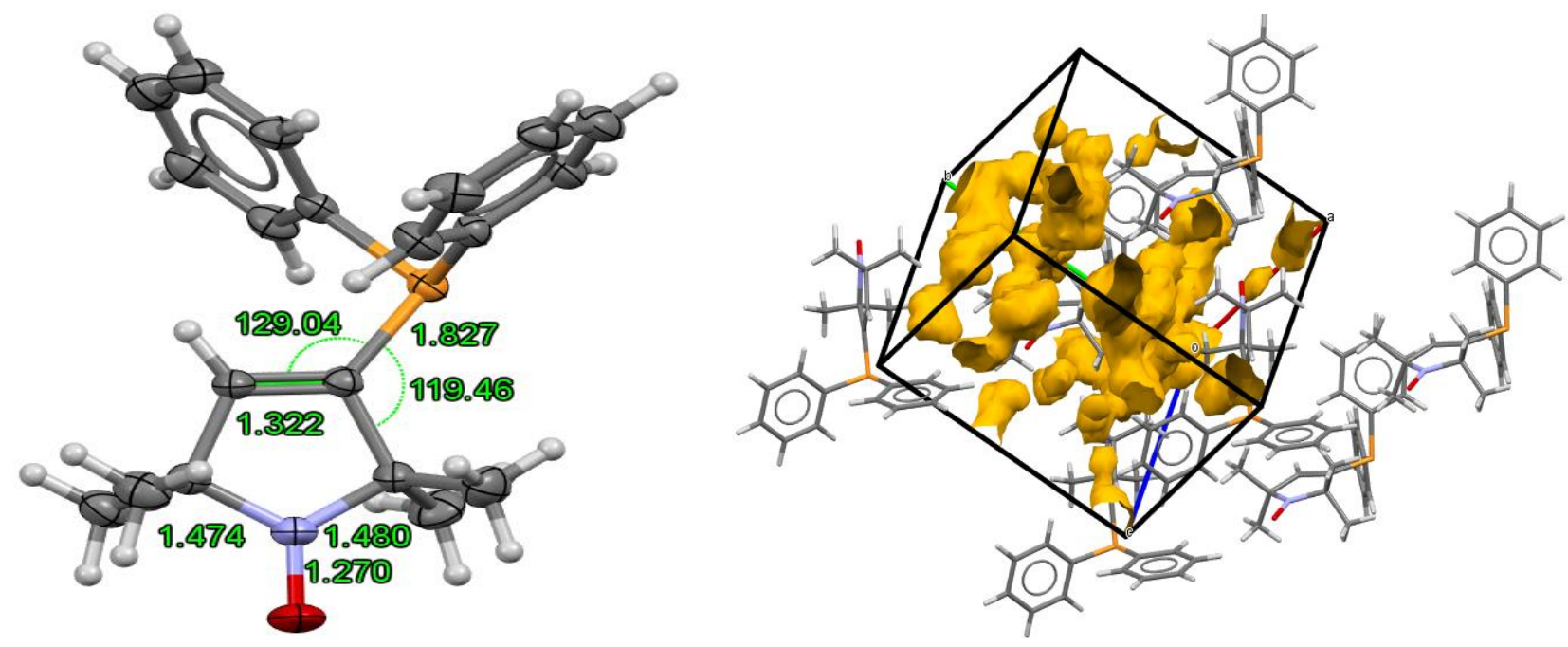

Figure 1. ORTEP view of 1 with selected bond length $(\AA)$ and angle $\left(^{\circ}\right)$ data (left) and packing diagram (right) showing voids with a small probe.

[1] Groom, C.R., Bruno, I.J., Lightfoot, M.P., Ward, S.C. (2016), Acta Cryst. B72, 171-179 .DOI: 10.1107/S2052520616003954

[2] Isbera, M., Bognár, B. Gallyas, F., Bényei, A. Jekő, J. \& Kálai, T. (2021). Molecules, in press.

[3] Andreidesz, K.,Szabó, A., Kovács, D., Kőszegi, B.,Vantus, V.B., Isbera, M., Kálai, T., Bognár, Z., Kovács, K., Gallyas, F. (2021). International Journal of Molecular Sciences, submitted for publication

Keywords: supramolecular structure; nitroxide; tertiary phosphane; biological effect

Acknowledgement: This research was funded by the Excellence Programme of the Ministry of Human Capacities in Hungary, within the framework of the 2020-4.1.1.-TKP2020. 